\title{
Improving Teamwork Skills of the Students by Extra Curricular Activities
}

\author{
Lacramioara Diana ROBESCU \\ University POLITEHNICA of Bucharest, Bucharest, Romania \\ diana.robescu@upb.ro \\ Elena Elisabeta MANEA \\ University POLITEHNICA of Bucharest, Bucharest, Romania \\ elena.manea@upb.ro
}

\begin{abstract}
Teamwork skills become increasingly a pre-requisite for employment success. All employers want to recruit graduates who are able to cooperate, share ideas and knowledge, solve problems, quickly adapt to new situation and work in teams. Romanian educational system is mainly based on the individual study, but it has to adapt to this request. The paper presents two different extra curricular activities that were organized in University POLITEHNICA of Bucharest, Faculty of Power Engineering, in order to develop these skills on the students. The students had to work together two weeks to develop a project, but in one of them they worked without having to physically be together at all times, by using the internet as the main communication method. Both events involved students or young graduates from different countries. The Romanian students never had an experience like these before, they were very enthusiastic and they really appreciated the skills and knowledge gained in these events.
\end{abstract}

Keywords: team working, elevator pitch, extra curricular activities, project

\section{INTRODUCTION}

A lot of papers have been devoted to investigate the necessity and importance of using group work in students programs. It is very important that students in engineering learn to work in a team, but this skill is not explicitly taught in the Romanian educational system. After the students graduated they have difficulties in their job because the employers expect they have this skill.

Engineering is by nature a collaborative process and most production systems are designed by teams working over long periods of time, but most programs in engineering do very little to develop this skill of the students, (Lingard, 2010). Adams et al (2014) reported the 
experiences of an instructional team at Arizona State University that introduced a new module on conation in a mandatory freshman engineering education course. The study illustrates how the inclusion of conation in the classroom can have a significant impact on students and teamwork experience. Sharp (n.d.), demonstrated using Kolb's theory by the students to work in lab teams or to audience analysis and strategies for writing and speaking.

The students can improve teamwork skill by participation in different extra curricular activities, like team projects and team competitions. This paper presents two experiences of Romanian students from Environmental Engineering undergraduate and master programs of Faculty of Power Engineering, University POLITEHNICA of Bucharest and foreign students from different countries, that improve teamwork skill of the students and at the same time enhance their presentation and communication skills.

\section{WETSKILLS CHALLENGE}

Wetskills Water Challenge is an international student exchange program that lasts two weeks (www.wetskills.com). The participants work in mixed teams of international students to develop original innovative concepts for water related case-studies sponsored by organizations within the water sector. In multidisciplinary and intercultural teams, the participants gain more in-depth knowledge on the challenge topic by workshops of renowned water experts and field trips. In addition, a special attention is paid to the development of presentation skills and collaboration among the team members.

In 2013, this challenge took place in Bucharest and it was connected to Regional Water Forum. There were twelve selected participants from University Politehnica of Bucharest and Technical University of Civil Engineering that worked together, in five mixed teams, with students from Dutch universities (Wageningen University, Utrecht University, VU University Amsterdam, TU Delft) and one young professional from Waterschapsbedrijf Groningen, an organization on water related issues. Each team had to focus on one specific case study, on which they work during an extensive two-week program.

The program started with a team-building event outside Bucharest. It involved a study trip at Wastewater Treatment Plant of Campulung and a "breaking the ice" weekend spent by students teams together at the mountain.

In the first working day the participants got a training of making an attractive Poster and presenting an inspiring so-called "Elevator Pitch". Elevator pitch is usually used in business context. It is a very important communication tool and for this competition it was designed to give the audience and jury concise and clear information about the idea of the project and made them interested in the subject. It represented a starting point of the questions and comments. A good elevator pitch should last no longer than a short elevator ride of 20 to 30 seconds, hence the name, ("Crafting an Elevator Pitch", n.d.), ideally less than 60 seconds, (Parsons, n.d.). 
The case studies were formulated by organizations of the Dutch water sector (Berson UV, Waterschapsbedrijf Limburg, HoogheemraadschapRijnland, MARS and UTES consortium, consisting of Dutch and Romanian organizations) and they tackled very actual problems in water sector, (Manea et al., 2013): Small-scale sludge treatment techniques, Management of Aquifer Recharge and Storage (MARS), Macro algae in the Black Sea, Satellite treatment of drinking water, Underground Thermal Energy and Storage (UTES).

In the first two working days each teams developed its Plans of Actions, well justified and researched, and presented it to the experts and to the supervisors. They are guided for their future work in order to develop an innovative solution for the case-study. The teams used extensively laptops and internet and they worked around on a table, Figure 1.

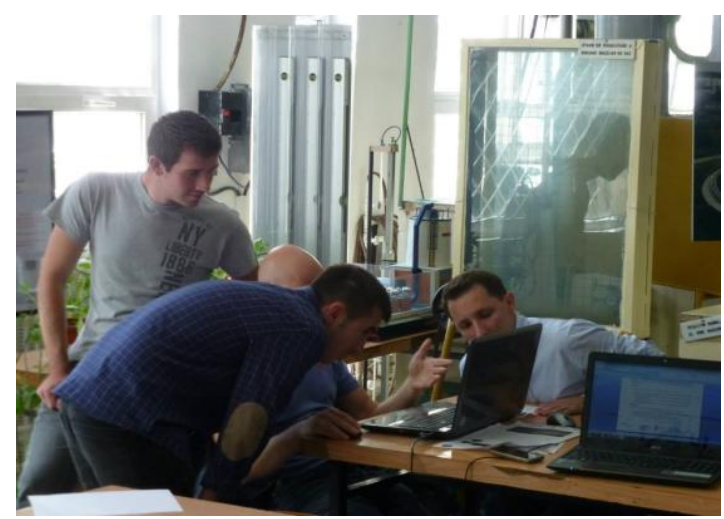

Figure 1: Team working.

A pre-presentations event was held a few days before the final presentation. Each team presented the draft - poster and the pitch and it was advised by other teams, experts and case sponsor to improve the posters.

At the end of the two-week pressure cooker, each team had to present to a judge committee their solution with an attractive Poster and a catching 'Elevator Pitch' in the framework of Regional Water Forum.

The participants were required to complete a questionnaire of 21 questions in order to know their opinion regarding the experience in Wetskills Challenge and to find the paths to improve the overall program of the challenge. They are asked about accommodations, working locations, support from the supervisors and from the case providers, teambuilding, working days, workshops/presentations/pre-presentations, official finals, their expectations, their feeling about professional career development, personal development, teamwork skills development. Furthermore, they are required to name two things good and two things that could be better and that should be changed in the next program. 
Figure 2 shows the students responses about their expectations regarding Wetskills Challenge on the scale from Excellent to Poor. Most of the students were very enthusiastic, but some of them didn't have any prior expectations from this competition, they only hoped to learn things about their profession. One student said: "Wetskills Water Challenge - Romania 2013 not only met up with my expectations, but it exceeded them by far. It is definitely much more than just a case study competition, because it focuses not only on problem solving, but especially on the social and networking component, which is far more important for a starting or an early stage career" and another one: "Personally, from this Wetskills, I received more than I've expected. I thought it's going to be like another workshop, meet new people, spend two weeks working and then goodbye. But, actually it was a great experience. Now, I know more about Dutch people and The Netherlands. Somehow, in only two weeks we bended to well, become friends and it's pity that it ended so fast".

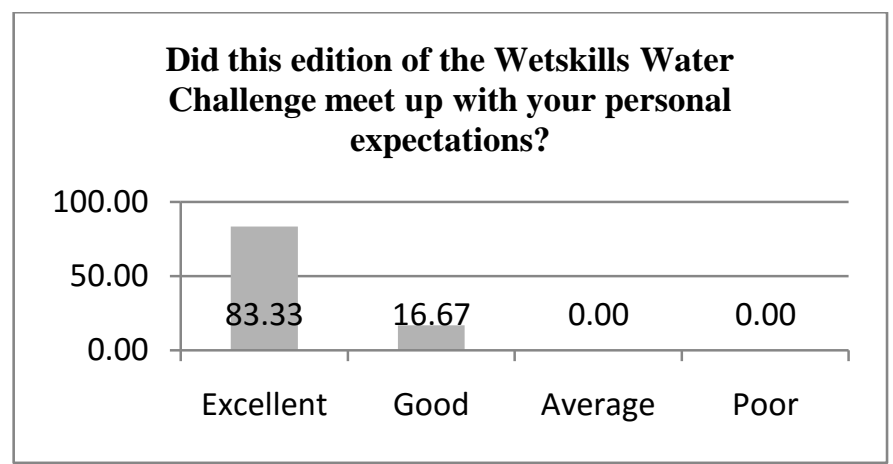

Figure 2: Students responses about their expectations regarding Wetskills Water Challenge.

About the help of this challenge in their professional career, students are generally satisfied, Figure 3. They think that Wetskills helped them in professional career by growing intellectual skills and education level.

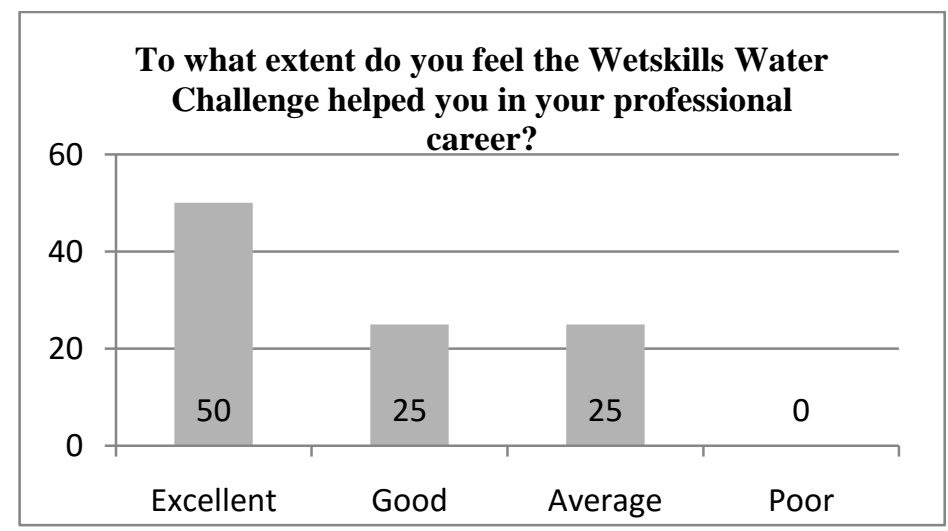

Figure 3: Students responses about Wetskills Water Challenge help in their professional career. 
A student that participated in two editions of Wetskills wrote: "Wetskills help me to improve my knowledge related to my field, my English, to speak in public and to think out of the box". However, there are some distrustful students regarding competition's help in their career in Romania, even though they learnt a lot.

In terms of the quality of the cases that they have worked on, students were very satisfied. They have to grade on a scale of 1 to $5: 5$ being the most enthusiastic agreement. Almost $84 \%$ of students responded 4 or 5 .

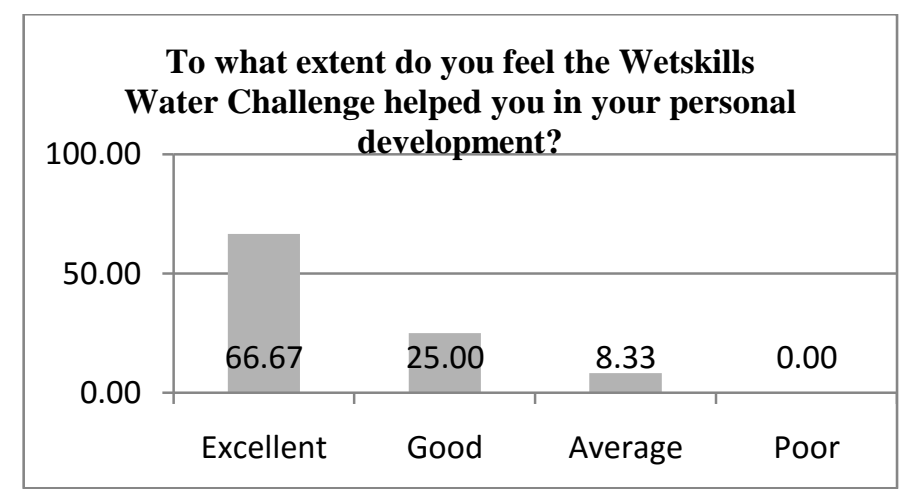

\section{Figure 4: Students responses about Wetskills Water Challenge help in their personal development.}

However, about the help of the case providers, their opinions are very different. Approximately $63 \%$ of the students responded 4 or 5 . Some of the case owners were always there for the team, ready to answer any question and facilitated work on the case, but some teams could not interact with the providers of study case or they had only one Skype meeting and a lot of unanswered questions.

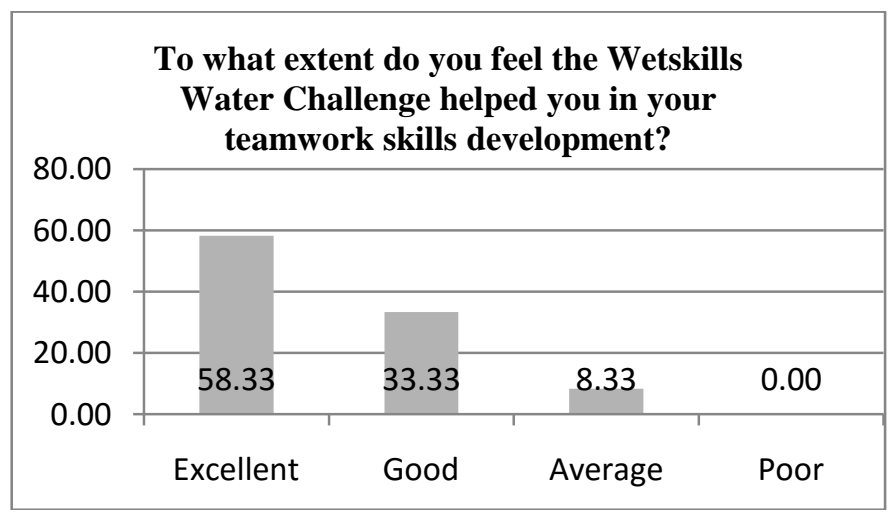




\section{Figure 5: Students responses about Wetskills Water Challenge help in their teamwork skills development.}

Generally, the students felt that this competition helped them in their personal development, Figure 4 and in team work skills development, Figure 5. A Romanian student commented that "This program challenged my social skills and knowledge and driven them to a higher level" and a Dutch student said she learnt "helping others, managing the group, learn how to hold peace in the group, and make choices that can be a bit selfish but better for the group and explain them".

The feedback about the ratio of teambuilding/excursions, working days, workshops and the official event was very positive. All the students answered Excellent or Good on the question "What is your opinion on the ratio of teambuilding/excursions, working days, workshops and the official event?". One student said: "All those events were like baby steps to help us know each other and helped us to be united so that we have better results". Almost all of them mentioned teambuilding trip one of very good thing about the program that should be remain part of it.

A very encouraging support for this challenge was shown by all participants. All of them would recommend the program to other student or Young Water Professionals because, as one of them said, this event was "The best working-learning-fun experience ever!".

\section{WATER ESSAYS COMPETITION}

Water Essays Competition was also two-week international, which was organized in 2013, based on the experience gained in Wetskills. The topic was "Smart solutions for water industry". The teams had to develop the essays in the two-week time, but unlike Wetskills without having to physically be together at all times, by using the internet as the main communication method. The aim of having this kind of cooperation was to create the possibility to have as participants students form more than two countries, thus having teams with varied backgrounds and experiences.

The competition aimed at identifying fresh solution for unresolved problems in the water sector and to develop young professional's skills and capacities for team working. Teams of four students had to elaborate an essay on a given topic. Each essay had to obey a given template and had to be at most six pages long. There was registered 32 students and young water professionals, that made 8 teams, from Romania, Bulgaria, Albania, Serbia, Moldavia, Burkina Faso, Palestine and Uganda. They presented the essays focused on very modern themes: Hydraulic Fracturing Impact on Water Resources Quality, "In situ" Methods Against Eutrophication, Cyanide Hazards from Gold Mining to Water Issues, Using Nanotechnologies in Wastewater Treatment, Solutions for Positive Energy Wastewater Treatment Plants for Temperate Areas, Water Supply and Wastewater Treatment in Cities of the Future, Influences from Antiquity to the Modern Water and Wastewater Treatment and Future in Obtaining Alternative Fuels from Wastewater Treatment Processes. 
All essays were introduced to the jury in 5 minutes during The International Conference on Energy and Environment. The accent in the essays was put on the originality and innovativeness of the solutions. At least one team member had to be present in the final competition day to present the essay, but there were present at least three members of each team. Also, a lot of students were in the public.

Participants were requested to complete a questionnaire of 18 questions. The main purpose of the analysis was to investigate weaknesses of the program and where are the points in need of improvement for the following editions.

Because all interactions were online, two teams out of eight could not communicate successfully and task assessment was done without all the team members coming to an agreement. They said that it is better when the participants are working face-to-face. That was an unexpected problem taken into account that in the competition were involved young people. They couldn't manage to work as a team because, as one of participant wrote, "We didn't agree on a communication channel until very late in the competition; different timetables coupled with some general unavailability resulted in very little opportunities for communication.”.

Almost all participants thought that competition helped them in professional career, personal development and teamwork skills development. One of the students said "From this experience I learned to listen carefully to my co-workers and to understand their needs and ideas.". But, not all agreed that the competition met their personal expectations. Some of them felt the competition like an experiment.

With its weaknesses and strengths, the competition was still a success taken into consideration that all participants said that would recommend it to other students and young water professionals. However, it is necessary to rethink the competition framework, particularly the working of teams in a virtual environment.

\section{DISCUSSION}

The two types of competitions, face-to-face and online, were well received by participants, but some of them thought that "brings people together physically as well, since communicating and working together is generally more effortless".

Wetskills started with a teambuilding and study trip, when the participants developed friendships and the teams started bonding. This initial phase was missed in online competition and probably this is one contributing factor for the poor performance of some teams.

Generally, in both competitions the teams worked very well together to generate an innovative solution, in Wetskills Water Challenge, or an attractive original essay in Water Essays Competition. 
The competitions had a positive influence on participants' networking and social development, but also on their professional career and teamwork skills. Nevertheless, the framework of Water Essays Competition should be improved by creating opportunities for easily remote collaborative work of the teams.

\section{CONCLUSIONS}

The knowledge exchange in a team has already been proven as being the best way for capacity development. The team competition represents a viable solution for preparing the students for a future in research and development companies.

The competitions described above had an extremely positive impact on personal development, professional career and teamwork skills of the participants as almost all of them desired to repeat the experience and recommend the programs to other students and young professionals. Furthermore, they improved their presenting and communication skills. The participants challenged to work in unusual working environment and under pressure. The competition between teams was high and making a difference between the teams was almost impossible, so that the mission of the jury was very difficult. Each case solution, respectively essay, had its importance and up points.

The competitions also lead to development of knowledge on the Romanian water sector, wastewater treatment, sewerage systems, renewable energy sources and environmental impact.

\section{REFERENCES}

Adams, E.A., Antaya, C.L., Seager, T.P. \& Landis, A.E. (2014). Improving learning productivity and teamwork skills in freshman engineering students through conative understanding. $121^{\text {st }}$ ASEE Annual Conference \& Exposition, Indianapolis. Retrieved September 4 4, 2015 from http://www.researchgate.net/profile/Claire_Dancz/publication/272168707_Improving_lear ning_productivity_and_teamwork_skills_in_freshman_engineer-

ing_students_through_conative_understanding_Improving_learning_producti

vity_and_teamwork_skills_in_freshman_engineering_students_through_conative_understa nding/links/54dd12dd0cf282895a3b4297.pdf

Lingard, R.W. (2010). Improving the Teaching of Teamwork Skills in Engineering and Computer Science. Systems, Cybernetics and Informatics, 8(6), 20-23. Retrieved September 4, 2015, from http://www.iiisci.org/Journal/CV\$/sci/pdfs/MJ682WA.pdf

Manea, E., Oost, J., Diels, J. (2013). Wetskills-Romania 2013. Romaqua,4, 10-14.

Parsons, N. (n.d) The 7 Key Components of a Perfect Elevator Pitch. Retrieved September 4, 2015, fom http://articles.bplans.com/the-7-key-components-of-a-perfectelevator-pitch/ 
Sharp, J.E. (n.d.) Learning styles and technical communication: improving communication and teamwork skills. Retrieved September 4, 2015, from http://citeseerx.ist.psu.edu/viewdoc/download?doi=10.1.1.41.4939\&rep=rep1\&type=pdf

Crafting an Elevator Pitch. (n.d) Retrieved September 4, 2015, from http://www.mindtools.com/pages/article/elevator-pitch.htm 